\section{Commentary: The Japan Cardiovascular Surgery Database: An important source of information regarding acute type A aortic dissection}

\author{
Nicholas T. Kouchoukos, MD
}

Okita and colleagues ${ }^{1}$ provide an update on the outcomes of surgery for acute type A aortic dissection from the Japan Cardiovascular Surgery Database (JCVSD). This database was established in 2001, and currently accumulates data from 591 surgical centers in Japan, with coverage estimated to exceed $95 \%$ of cases. The present report encompasses 29,486 patients with acute type A aortic dissection who were treated between 2013 and 2018.

Among the notable findings in this study: a substantial increase in the annual number of cases treated during the 6-year interval, despite a decline in the population of Japan; an essentially stable early mortality rate, ranging between $10.1 \%$ and $12.1 \%$; a decline in the percentage of patients who required prolonged assisted ventilation; and no appreciable change in the prevalence of stroke, spinal cord ischemic injury (SCI), or need for new dialysis. The overall early mortality rate is appreciably lower than the rates recently reported from the other large databases for acute type A aortic dissection (Society of Thoracic Surgeons, German Registry for Acute Aortic Dissection Type A, International Registry of Acute Aortic Dissection, and NOORCAD (Nordic Consortium for Acute Type A Aortic Dissection), that have ranged from $16.9 \%$ to $18.9 \% .^{2-5}$ The reasons for this lower early mortality remain unclear, but the authors do note the smaller body mass index of many of their patients, and a substantially lower number

\footnotetext{
From the Division of Cardiovascular and Thoracic Surgery, Missouri Baptist Medical Center, BJC Healthcare, St Louis, Mo.

Disclosures: The authors reported no conflicts of interest.

The Journal policy requires editors and reviewers to disclose conflicts of interest and to decline handling or reviewing manuscripts for which they may have a conflict of interest. The editors and reviewers of this article have no conflicts of interest.

Received for publication Oct 5, 2020; revisions received Oct 5, 2020; accepted for publication Oct 6, 2020; available ahead of print Sept 12, 2020.

Address for reprints: Nicholas T. Kouchoukos, MD, Division of Cardiovascular and Thoracic Surgery, Missouri Baptist Medical Center, 3023 N Ballas Rd, Suite 150D, St Louis, MO 63131 (E-mail: ntkouch@aol.com).

J Thorac Cardiovasc Surg 2022;164:798-9

$0022-5223 / \$ 36.00$

Copyright $(2) 2020$ by The American Association for Thoracic Surgery

https://doi.org/10.1016/j.jtcvs.2020.10.027
}

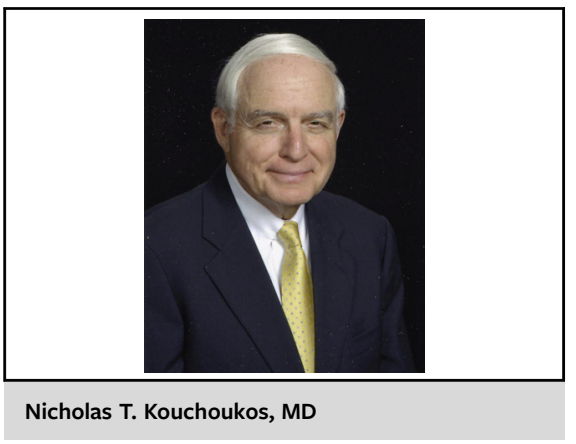

\author{
CENTRAL MESSAGE \\ This report contains important \\ data on the current surgical \\ treatment of acute type A aortic \\ dissection in Japan. The infor- \\ mation will be useful to other \\ nations that seek to improve \\ their outcomes.
}

of patients who underwent aortic valve or aortic root replacement or repair when compared with the other major databases. In the present JCVSD study, among the patients in whom the aortic valve or root was not repaired or replaced ( $90 \%$ of the total group), the early mortality rate was $10.4 \%$, whereas for the 2332 patients who had aortic valve replacement or a Bentall procedure, the early mortality was $23.1 \%$ (539 patients). Longer follow-up of the patients in this database will determine whether this conservative strategy will result in repairs that are durable.

Another important difference when compared with the other large databases is a more aggressive policy toward extended aortic arch replacement. As the authors note, this is related at least in part to adoption of the frozen elephant trunk (FET) procedure that was used in 35\% of the extensive arch replacements. Of note, no difference in early mortality, stroke, SCI, or prolonged ventilation was noted between the hemiarch and extended arch replacement groups. However, use of the FET procedure was associated with a $6.5 \%$ incidence of SCI, a rate that was significantly higher than the $3.5 \%$ incidence for the hemiarch group, and the $4.4 \%$ incidence for the extended arch group without an FET. The rate of SCI associated with the FET noted in this and other reports ${ }^{6,7}$ remains a cause for concern.

The cardiovascular surgeons responsible for development of the JCVSD are to be commended for their efforts. 
This database continues to yield immensely important information on the outcomes following cardiovascular surgical procedures for virtually the entire population of Japan, as well as information that will be of value to other nations that are striving to improve outcomes following the treatment of acute type A aortic dissection and other major vascular and cardiac surgical procedures.

\section{References}

1. Okita Y, Kumamaru H, Motomura N, Miyata H, Takamoto S. Current status of open surgery for acute type A aortic dissection in Japan. J Thorac Cardiovasc Surg. 2022;164:785-94.e1.

2. Helder MRK, Schaff HV, Day CN, Pochettino A, Bagameri G, Greason KL, et al. Regional and temporal trends in the outcomes of repairs for acute type A aortic dissections. Ann Thorac Surg. 2020;109:26-35.
3. Conzelmann LO, Weigang E, Mehlhorn U, Abugameh A, Hoffmann I Blettner M, et al. Mortality in patients with acute aortic dissection type A: analysis of pre- and intraoperative risk factors from the German Registry for Acute Aortic Dissection Type A (GERAADA). Eur J Cardiothorac Surg. 2016;49: e44-52.

4. Evangelista A, Isselbacher EM, Bossone E, Gleason TG, Di Eusanio M, Sechtem E, et al. Insights from the International Registry of Acute Aortic Dissection. A 20-year experience of collaborative clinical research. Circulation. 2018; 137:1846-60

5. Olssona C, Ahlsson A, Fuglsan S, Geirsson A, Gunn J, Emma C. Medium-term survival after surgery for acute type A aortic dissection is improving. Eur J Cardiothorac Surg. 2017;52:852-7.

6. Preventza O, Liao JL, Olive JK, Simpson K, Critsinelis AC, Price MD, et al Neurologic complications after the frozen elephant trunk procedure: a meta-analysis of more than 3000 patients. J Thorac Cardiovasc Surg. 2020;160: 20-33.e4.

7. Kouchoukos NT. Commentary: Is it time to thaw the frozen elephant trunk procedure? J Thorac Cardiovasc Surg. 2020;160:35-6.

\title{
Commentary: Type A dissection repairs made in Japan
}

\author{
Steven L. Lansman, MD, PhD
}

Okita and colleagues ${ }^{1}$ report a very large, contemporary (2013 to 2018) experience drawing from 29,486 surgical cases of acute type A aortic dissection (AAD) registered in the Japan Cardiovascular Database. Reporting all cases to the national database is mandatory in Japan, so the data are a representative acute cohort.

There is valuable information in this article. Although frequently the subject of research, the aortic arch was replaced in only $20.6 \%$ of AAD cases, with an additional $8.7 \%$ undergoing a concomitant frozen elephant trunk (FET) procedure. Outcomes were similar whether the extent of resection included zones 0 to I, 0 to III, or 0 to

\footnotetext{
From the Department of Cardiothoracic Surgery, Westchester Medical Center, Valhalla, NY

Disclosures: The author reported no conflicts of interest.

The Journal policy requires editors and reviewers to disclose conflicts of interest and to decline handling or reviewing manuscripts for which they may have a conflict of interest. The editors and reviewers of this article have no conflicts of interest.

Received for publication Sept 17, 2020; revisions received Sept 17, 2020; accepted for publication Sept 17, 2020; available ahead of print Sept 18, 2020.

Address for reprints: Steven L. Lansman, MD, PhD, Department of Cardiothoracic Surgery, Westchester Medical Center, 100 Woods Rd, Macy Pavilion 114W, Valhalla, NY 10595 (E-mail: Steven.Lansman@wmchealth.org).

J Thorac Cardiovasc Surg 2022;164:799-80

0022-5223/\$36.00

Copyright (c) 2020 by The American Association for Thoracic Surgery

https://doi.org/10.1016/j.jtcvs.2020.09.078
}

III + FET, with respect to hospital mortality $(10.8 \%$, $11.9 \%$, and $10.8 \%$, respectively), stroke $(11.5 \%, 11.9 \%$, and $11.5 \%$, respectively), and prolonged ventilation $(15.1 \%, 15.6 \%, 16.0 \%$, respectively). However, the incidence of spinal cord injury (SCI) was $3.3 \%, 4.4 \%$, and $6.5 \%$, respectively. Presumably, these are de novo, postoperative SCI complications because preoperative SCI is not noted. These data are notable at both ends of the resection spectrum. Despite a number of centers reporting very low 